\title{
A LONGITUDINAL ANALYSIS OF PHENOTYPIC AND SYMPTOM CHARACTERISTICS ASSOCIATED WITH INTER-INDIVIDUAL VARIABILITY IN EMPLOYMENT INTERFERENCE IN PATIENTS WITH BREAST CANCER
}

\author{
Raymond Javan Chan, RN, $\mathrm{PhD}^{1,2,3}$ \\ Bruce Cooper, $\mathrm{PhD}^{4}$ \\ Bogda Koczwara, MD ${ }^{5}$ \\ Alexandre Chan, Pharm D $\mathrm{D}^{6,7}$ \\ Chia Jie Tan, BPharm (Hons) $)^{6,7}$ \\ Steven M. Paul, $\mathrm{PhD}^{4}$ \\ Laura B. Dunn, MD ${ }^{8}$ \\ Yvette P. Conley, $\mathrm{PhD}^{9}$ \\ Kord M. Kober, $\mathrm{PhD}^{4}$ \\ Jon D. Levine, MD, $\mathrm{PhD}^{10}$ \\ Christine Miaskowski, RN, RN, PhD 4 \\ ${ }^{1}$ School of Nursing, Queensland University of Technology, Kelvin Grove, Q4059, Australia \\ ${ }^{2}$ Institute of Health and Biomedical Innovation, Queensland University of Technology, Kelvin \\ Grove, QLD 4059, Australia \\ ${ }^{3}$ Princess Alexandra Hospital, Metro South Hospital and Health Services, Woolloongabba, QLD \\ 4102, Queensland, Australia \\ ${ }^{4}$ School of Nursing, University of California, San Francisco, San Francisco, CA, USA \\ ${ }^{5}$ Flinders Centre for Innovation in Cancer, Flinders Medical Centre and Flinders University, \\ Bedford Park, SA 5042, Australia \\ ${ }^{6}$ Department of Pharmacy, Faculty of Science, National University of Singapore, Block S4A, \\ Level 3, 18 Science Drive 4, Singapore 117543 \\ ${ }^{7}$ Department of Pharmacy, National Cancer Centre, 11 Hospital Drive, Singapore 169610 \\ ${ }^{8}$ School of Medicine, Stanford University, Stanford, CA, USA \\ ${ }^{9}$ School of Nursing, University of Pittsburgh, Pittsburgh, PA, USA \\ ${ }^{10}$ School of Medicine, University of California, San Francisco, San Francisco, CA, USA
}

Running head: Employment Interference in Breast Cancer Patients

Corresponding author

Christine Miaskowski, RN, PhD

Department of Physiological Nursing

University of California, San Francisco

2 Koret Way - N631Y

San Francisco, CA 94143-0610

Email: chris.miaskowski@ucsf.edu

Acknowledgements: The Oncology Nursing Foundation provided funding for this project. The original study was funded by grants from the National Cancer Institute $(\mathrm{NCl}, \mathrm{CA} 107091$ and CA118658). Dr. Miaskowski is an American Cancer Society Clinical Research Professor and has a K05 award from the NCI (CA168960). This project was supported by NIH/NCRR UCSFCTSI Grant Number UL1 RR024131. Its contents are solely the responsibility of the authors and do not necessarily represent the official views of the National Institutes of Health or the Oncology Nursing Foundation. 


\begin{abstract}
Purpose: A breast cancer diagnosis has a substantial economic impact. Study aims were to evaluate for inter-individual differences in cancer's level of interference with employment and identify phenotypic and symptom characteristics associated with higher levels of interference.
\end{abstract}

Methods: Patients $(n=387)$ were enrolled prior to breast cancer surgery and followed for 12 months. Interference with employment was measured using a 0 (no problem) to 10 (severe problem) numeric rating scale. Hierarchical linear modeling (HLM) was used to evaluate for inter-individual differences in trajectories of employment interference and characteristics associated with employment interference at enrollment and over 12 months.

Results: Patients' mean age was $55.0( \pm 11.7)$ years and the majority underwent breast conservation surgery (80.6\%). Mean employment interference score was $3.2( \pm 3.7)$.

Unconditional model for employment interference demonstrated a decreasing linear trend (-.076/month). Younger age, lower income, higher pain intensity, and having an axillary lymph node dissection were associated with higher pre-surgical interference scores. Having a sentinel lymph node biopsy was associated with ongoing employment interference scores. Higher sleep disturbance scores were associated with both initial and ongoing employment interference scores. Receipt of chemotherapy, use of complementary or alternative therapies, and reexcision or mastectomy following surgery were significant time varying covariates.

Conclusion: This study is the first to use HLM to describe inter-individual differences in the trajectories of cancer's interference with employment and associated factors prior to and for 12 months following breast cancer surgery. Patients with the identified risk factors warrant ongoing assessments of employment interference and appropriate referrals. 
Keywords: breast cancer; employment; interference; symptom burden; hierarchical linear modeling; financial toxicity 


\section{INTRODUCTION}

In the United States, an estimated 268,600 new cases of female breast cancer will be diagnosed in 2019 [1]. This cancer diagnosis and its treatment can have significant short- and long term impacts on patients' employment [2]. For example, in one study [3], compared to healthy controls, breast cancer patients were significantly less likely to be employed six months after diagnosis, and among those who continued to work, they worked fewer hours. Cancer's interference with employment is substantial and often extends beyond treatment and into survivorship regardless of whether the patient eventually returns to work [2].

Depending on an individual's personal situation and the treatments she receives, breast cancer patients report absenteeism from work, reduced work ability, limited work performance and career progression, and at times, voluntary termination of employment $[2,4]$. This interference with employment is associated with a higher financial burden [5]. In monetary terms, according to a recent analysis of the National Health Interview Survey conducted in the United States [6], for women with breast cancer, the foregone annual earnings were estimated at $\$ 2,293$ per capita for women aged $18-44$ years and $\$ 1,407$ per capita for women aged $45-64$ years.

A number of factors are associated with changes in employment after a breast cancer diagnosis. Patient factors such as lower levels of education and physical and mental health, as well as lack of support from colleagues and supervisor contributed to early retirement and nonemployment among breast cancer patients $[7,8]$. In terms of symptom burden, higher levels of pain [9], anxiety [10-14], fatigue [10-14], depression [10-14], and cognitive dysfunction $[15,11,14]$ were associated with higher employment interference after breast cancer treatment. Across these studies, employment interference was categorized as whether or not patients returned to work, retired, or reduced the number of hours worked after their cancer treatment [915]. One limitation of these categorizations is that they did not discriminate between whether these employment changes were due to the breast cancer diagnosis itself or the receipt of 
single (e.g., surgery alone) or multimodal (e.g., surgery and radiation therapy) treatments. In addition, these studies did not evaluate for changes over time in employment interference and associated predictors. Therefore, the purposes of this study were to evaluate for inter-individual differences in cancer's level of interference with employment among women with breast cancer from prior to through 12 months after surgery and identify phenotypic and symptom characteristics associated with higher levels of interference.

\section{METHODS}

\section{Patients and Settings}

This descriptive, longitudinal analysis is part of a larger National Cancer Institute funded study that evaluated for neuropathic pain and lymphedema in women who underwent breast cancer surgery [16]. Patients were recruited from Breast Care Centers located in a Comprehensive Cancer Center, two public hospitals, and four community practices. Patients were eligible to participate if they were women $\geq 18$ years of age who would undergo breast cancer surgery on one breast; were able to read, write, and understand English; agreed to participate; and gave written informed consent. Patients were excluded if they were having breast cancer surgery on both breasts and/or had distant metastases at the time of diagnosis.

\section{Instruments}

At enrollment, a demographic questionnaire obtained information on age, gender, marital status, level of education, ethnicity, employment status, and annual household income. Functional status was assessed using the Karnofsky Performance Status (KPS) scale [17]. Level of comorbidity was assess using the Self-Administered Comorbidity Questionnaire (SCQ). Possible scores can range from 0 to 39 [18].

For this study, interference with employment was assessed using a single item from the Quality of Life Scale-Patient Version (QOL-PV) [19], namely, "To what degree has your illness or treatment interfered with your employment?". Patients were asked to rate this item using a 0 (no problem) to 10 (severe problem) numeric rating scale (NRS). 
The Spielberger State-Trait Anxiety Inventories (STAI-S, STAI-T) were used to assess an individual's transitory emotional response to a stressful situation (i.e., right now), as well as his/her predisposition to anxiety, respectively. Scores for each scale are summed and can range from 20 to 80 . A higher score indicates greater anxiety. Cut off scores of $\geq 31.8$ and $\geq 32.2$ indicate high levels of trait and state anxiety, respectively [20]. In this study, Cronbach's alphas for the STAI-T and STAI-S were .88 and .95 , respectively.

The 20-item Center for Epidemiological Studies Depression Scale (CES-D) was used to evaluate the major symptoms in the clinical syndrome of depression. Scores can range from 0 to 60 , with scores of $\geq 16$ indicating the need for individuals to seek clinical evaluation [21]. In this study, its Cronbach's alpha was 0.90 .

The 18-item Lee Fatigue Scale (LFS) was used to assess physical fatigue and energy [22]. Each item was rated on a 0 to 10 NRS. Total fatigue and energy scores were calculated as the mean of the 13 fatigue and the 5 energy items. Higher scores indicate greater fatigue severity and higher levels of energy. Patients were asked to rate each item based on how they felt "right now". Cut-off scores of $\geq 4.4$ and $\leq 4.8$ indicate high levels of fatigue and low levels of energy respectively [23]. In this study, Cronbach's alphas for fatigue and energy scales were .96 and .93 , respectively.

The 16-item Attentional Function Index (AFI) was used to measure attentional function. Each item was rated on a 0 to 10 NRS. A higher mean score indicates greater capacity to direct attention. Scores are grouped into categories of attentional function (i.e., < 5.0 low function, 5.0 to 7.5 moderate function, $>7.5$ high function) [24]. In this study, its Cronbach's alpha was .95.

The 21-item General Sleep Disturbance Scale (GSDS) was used to assess the quality of sleep in the past week. Each item was rated on a 0 (never) to 7 (everyday) NRS. The GSDS total score is the sum of 21 items that can range from 0 (no disturbance) to 147 (extreme sleep disturbance). A GSDS total score of $\geq 43$ indicates a significant level of sleep disturbance [25]. In this study, its Cronbach's alpha was .86 . 
The occurrence of breast pain prior to surgery was determined by asking the question "Are you experiencing pain in your affected breast?" If women responded yes, they rated their average and worst pain using a 0 (no pain) to 10 (worst imaginable pain) NRS.

\section{Study Procedures}

The study was approved by the Committee on Human Research at the University of California, San Francisco and by the Institutional Review Board at each of the study sites. During the patient's preoperative visit, a clinical staff member explained the study to the patient and determined her willingness to participate. The staff member introduced women who were willing to participate to the research nurse. The research nurse met with the women, determined eligibility, and obtained written informed consent prior to surgery. After obtaining consent, patients completed the enrollment questionnaires an average of four days prior to surgery and at one, two, three, four, five, six, eight, ten, and twelve months after surgery. The research nurse met with the patients at the Clinical Research Center or in their homes. Patients' medical records were reviewed for disease and treatment information.

\section{Data Analysis}

Descriptive statistics and frequency distributions were computed for sample characteristics and symptom severity scores using SPSS version 23 (IBM, Armonk, NY). With the exception of the employment interference item from the QOL-PV and the time varying covariates (i.e., radiation therapy, chemotherapy, hormonal therapy, complementary/alternative therapy, breast reconstruction, and re-excision or mastectomy of the affected breast) which were assessed prior to surgery and at $1,2,3,4,5,6,8,10$, and 12 months after surgery), all of the demographic, clinical, and symptom characteristics that were evaluated as predictors in the hierarchical linear modeling (HLM) analysis were assessed prior to surgery.

Hierarchical linear modeling, based on full maximum likelihood estimation, was done using Stata/SE (StataCorp, 2017). In brief, the HLM analysis was done to evaluate for changes over time in ratings of "To what degree has your illness or treatment interfered with your 
employment?". First, intra-individual variability in employment interference over time was examined and the best fitting unconditional model was identified (no covariates in the model except time). Models were compared to identify the best fitting change trajectory (i.e., only linear or linear and quadratic effects) and the best fitting covariance structure for the random effects at level 2 (random intercepts only; or random intercepts, random slopes, and the covariance between intercepts and slopes - an "unstructured covariance matrix"). The criteria used to evaluate for "best fit" were a combination of significant vs non-significant fixed effects and the model with the smallest Akaike's Information Criterion (AIC) [26]. From these analyses, the best fitting unconditional model was estimated as a linear change trajectory with an unstructured covariance matrix for the level 2 random effects.

Second, inter-individual differences in the initial level of interference with employment (i.e., intercept predictors) were tested by examining associations with potential demographic, clinical, and symptom characteristics. Table 1 presents a list of the proposed predictors that was developed based on a review of the literature on employment interference in breast cancer patients [2]. To improve estimation efficiency and construct a joint model that was parsimonious, an exploratory level 2 analysis was completed in which each potential predictor was assessed to determine whether it would result in a better model if it alone were added as a level 2 predictor. Predictors were examined one-at-a-time to test their association with the initial level of employment interference (intercept predictor), as well as whether each predictor was associated with a change in employment interference over 12 months (slope predictor). This second effect is often called a "cross-level interaction" because it tests whether an effect at level 2 (e.g., a clinical characteristic measured once) is associated with an effect at level 1 (i.e., the linear change trajectory of employment interference over 12 months). For each potential predictor, both the fixed effects at enrollment and the cross-level interactions were tested with an alpha = .05. Those predictors that were not significant were dropped from subsequent model testing. 
Following these exploratory analyses, all significant effects at enrollment and significant crosslevel interactions were entered into a joint model.

Missing data for employment interference were accommodated through the use of full information maximum likelihood (FIML). Hierarchical linear modeling provides unbiased estimates of change or of the effect of predictors on change even if some assessments of the outcome are missing or patients drop out of the study. This accommodation is possible through the use of FIML [27] with the Expectation-Maximization (EM) algorithm [27]. This method provides unbiased parameter estimates as long as the missingness is ignorable. Even if patients only provide data at the initial assessment, their data contribute to the estimation of the intercept (e.g., mean score at enrollment) and intercept variance. Patients contributed information to the analysis for as many times as they provided data. The missing data that did occur was assumed to be missing at random (one form of "ignorable missingness") [27].

\section{RESULTS}

\section{Sample Characteristics}

A total of 516 patients were approached and 410 enrolled in the study (response rate $79.5 \%$ ). For the current analysis, complete data from 387 women were available. For those women who declined participation (20.5\%), the major reasons for refusal were: too busy, overwhelmed with their cancer diagnosis, or insufficient time available to complete the initial assessment prior to surgery.

The patients' demographic, clinical, and symptom characteristics at enrollment are listed in Table 2. On average, patients were 55 years of age, well educated, within 3 months of their diagnosis, had a good functional status, and a SCQ score of 4.2. Most of the women were White $(65.6 \%)$ and post-menopausal (64.9\%). Forty-one percent of the patients were married or partnered and $48.1 \%$ were working for pay. Over $80 \%$ underwent breast conservation surgery. The mean employment interference score prior to surgery was $3.2( \pm 3.7$; range 0 to 10$)$.

\section{Individual and Mean Change in Interference with Employment}


The first stage of the HLM analysis examined how employment interference changed from prior to through 12 months after surgery (Table 3). The intercept represents the estimated level of interference with employment (i.e., 3.538 on a 0 to 10 scale) at the preoperative assessment. The estimated linear rate of change in cancer's interference with employment, for each additional month, was $-0.076(p<0.001)$. Figure $1 \mathrm{~A}$ displays the trajectory for cancer's interference with employment from the preoperative assessment to 12 months after surgery. Cancer's interference with employment decreased over the course of 12 months. The mean levels of cancer's interference with employment scores for the various groups depicted in Figures 1 and 2 are estimated or predicted means based on the HLM analysis.

\section{Inter-individual Differences in the Trajectories of Interference with Employment}

The second stage of the HLM analysis evaluated how the pattern of change over time in cancer's interference with employment varied based on specific phenotypic and symptom characteristics (Table 1). As shown in the final model in Table 3, the characteristics that predicted inter-individual differences in preoperative levels of cancer's interference with employment were age, income, axillary lymph node dissection (ALND) and worst pain intensity score in the breast prior to surgery. Having a sentinel lymph node biopsy (SLNB) predicted inter-individual differences in the slope parameter estimates for cancer's interference with employment. Sleep disturbance predicted inter-individual differences in both the intercept and slope parameter estimates for cancer's interference with employment.

To illustrate the effects of the above predictors on patients' initial levels and trajectories of cancer's interference with employment, Figures 1B, 1C, 1D, and 1E display the adjusted change curves for cancer's interference with employment that were estimated based on differences in age (i.e., younger/older age calculated based on one SD above and below the mean age), levels of income prior to surgery (i.e., lower/higher levels of income calculated based on one SD above and below the mean income level), occurrence of an ALND (yes or no), and pain (i.e., lower/higher levels of worst pain calculated based on one SD above and below 
the mean worst pain scores), respectively. Figures $2 \mathrm{~A}$ and $2 \mathrm{~B}$ display the adjusted change curves for cancer's interference with employment that were estimated based on differences in occurrence of a SLNB (yes or no) and levels of sleep disturbance (i.e., lower/higher levels of sleep disturbance calculated based on one SD above and below the mean GSDS score).

In terms of the time varying covariates, of the six that were evaluated, only three remained significant in the final model (Table 3). Over the 12 month period of the study, the receipt of chemotherapy, the use of complementary and alternative therapies, and the occurrence of re-excision or mastectomy, at some time during the 12 months, were associated with greater interference with employment.

\section{DISCUSSION}

This study is the first to use HLM to examine inter-individual variability in the trajectories of cancer's interference with employment from prior to through 12 months after breast cancer surgery and to investigate whether demographic, clinical, and symptom characteristics predicted preoperative levels and changes in the trajectories of cancer's interference with employment. Consistent with previous reports [28,29], cancer's interference with employment decreased slowly over time. While $40.8 \%$ of patients in this study reported that they were not working for pay prior to surgery, we cannot determine whether unemployment at this point in the disease trajectory was attributable to the cancer diagnosis or previous (i.e., $21.7 \%$ of the patients had neoadjuvant chemotherapy) or future treatments. However, we overcame the issue of attributability by directly asking patients to rate their cancer's interference with employment over 12 months instead of assessing self-reported sick leave or return to work.

Age, income, ALND, and pain intensity were associated with inter-individual differences in cancer's interference with employment at enrollment. In this study, younger age and lower income were associated with higher levels of employment interference. Consistent with previous reports [10,30-32], people with a lower income are more likely to report unemployment or employment issues after cancer. In contrast, the relationship between age and employment 
changes, in women with breast cancer, is less clear with one study finding that older age limited or delayed return to work [33] and another study showing that younger age was associated with increased sick leave [34]. One potential explanation for our finding is that women who are younger may have higher expectations about being able to return to work and a stronger desire to progress in their careers [35]. To examine this relationship further, future studies need to incorporate both patient-reported employment interference and objective (e.g., absenteeism, decreases in work hours) measures. An additional consideration, particularly for women, is an evaluation of work productivity even if they are not in the workforce (i.e., unpaid productivity).

In this study, while ALND was an intercept predictor, SLNB was a predictor of the slope. Compared to having a SLNB (Figure 2A), the receipt of an ALND has a relatively larger impact on patients' interference with employment (Figure 1D). This finding is expected because an ALND is associated with more severe adverse effects (e.g., upper limb morbidity, immobility associated with axillary pain and arm swelling $[29,28,36])$ which may limit patients' ability to return to normal activities and employment [29]. The relationship between having a SLNB and employment interference is less clear (Figure 2A). The finding that not having a SLNB was associated with an increasing trajectory of employment interference may be partially explained by the fact that $5.4 \%(21 / 387)$ of the women who did not have a SLNB did have an ALND at the time of surgery.

Consistent with findings from a systematic literature review [2], in the exploratory analysis, a number of symptoms including depression, anxiety, fatigue, cognitive impairment, sleep disturbance and pain (Table 1) were associated with inter-individual differences in cancer' interference with employment at enrollment. However, only pain and sleep disturbance were retained in the final model. Preoperative breast pain may be associated with higher levels of employment interference because in our previous work we found that women with this type of pain reported higher levels of depression [16], anxiety [16], sleep disturbance [16], and disability [37]. Regarding sleep disturbance (Figure 2B), higher preoperative levels of sleep disturbance 
were associated with higher levels of employment interference that decreased slowly over time. In contrast, lower levels of sleep disturbance at enrollment, were associated with slight increases in employment interference over time. The factors that influence the relationships between sleep disturbance (e.g., use of effective sleep hygiene strategies [38], changes in anxiety [39]) and employment interference warrant additional investigation.

Receipt of chemotherapy, use of complementary or alternative therapies, and reexcision or mastectomy of the affected breast after the initial surgery were the time varying covariates that were associated with higher levels of employment interference. Plausible explanations for the positive associations between the receipt of chemotherapy, or re-excision or mastectomy and employment interference include: work interruptions to receive chemotherapy, management of treatment related side effects, and the time required to recover from the additional surgical procedure(s). It is possible that women who used complementary or alternative therapies had more severe side effects $[40,41]$ that required them to take time off from work. These findings suggest that clinicians need to perform ongoing assessments to determine the impact of breast cancer treatments' on employment interference and initiate appropriate referrals.

One of this study's limitations is that objective measures of employment interference (e.g., returning to work, reduced work hours, sick leave) were not collected. Instead, this study focused on patients' assessment of cancer's interference with employment which allowed us to assess inter-individual variability in this outcome. In addition, information on the patients' occupations which could influence their ability to return to work was not collected. Finally, given differences across countries in terms of insurance coverage and sick leave benefits, our findings may not generalize to other countries with more restrictive or liberal benefits.

In terms of clinical implications, evidence exists that multidisciplinary interventions, that include physical, psycho-educational, and vocational components can assist cancer patients to return to work [42]. Therefore, clinicians need to assess for employment interference and 
engage in discussions regarding plans for returning to work and alternative careers and opportunities; make referrals to social services; and provide practical information (e.g., legal rights) [43]. In addition, the use of effective symptom management interventions, particularly for pain and sleep disturbance, may decrease the impact of cancer and its treatment on employment interference. 
Figure legends

Figure 1. Trajectory of cancer's interference with employment $(A)$ and influence of age $(B)$, income (C), axillary lymph node dissection (D), and pain (E) on inter-individual differences in the intercept parameters for cancer's interference with employment.

Figure 2. Influence of sentinel lymph node biopsy (A) and sleep disturbance (B) on interindividual differences in the slope parameters for cancer's interference with employment. 
Conflict of Interest - The authors declare no conflicts of interest. The authors had full control over the data and will allow the journal to review our data if requested to do so. 


\section{REFERENCES}

1. National Cancer Institute (2019) SEER Cancer Stat Facts: Female Breast Cancer. https://seer.cancer.gov/statfacts/html/breast.html. Accessed 19-04-2019

2. Sun $Y$, Shigaki CL, Armer JM (2017) Return to work among breast cancer survivors: $A$ literature review. Support Care Cancer 25 (3):709-718. doi:10.1007/s00520-016-3446-1

3. Bradley CJ, Neumark D, Bednarek HL, Schenk M (2005) Short-term effects of breast cancer on labor market attachment: results from a longitudinal study. J Health Econ 24 (1):137-160. doi:10.1016/j.jhealeco.2004.07.003

4. Jagsi R, Abrahamse PH, Lee KL, Wallner LP, Janz NK, Hamilton AS, Ward KC, Morrow M, Kurian AW, Friese CR, Hawley ST, Katz SJ (2017) Treatment decisions and employment of breast cancer patients: Results of a population-based survey. Cancer 123 (24):4791-4799. doi:10.1002/cncr.30959

5. Pearce A, Tomalin B, Kaambwa B, Horevoorts N, Duijts S, Mols F, van de Poll-Franse L, Koczwara B (2019) Financial toxicity is more than costs of care: the relationship between employment and financial toxicity in long-term cancer survivors. J Cancer Surviv 13 (1):10-20. doi:10.1007/s11764-018-0723-7

6. Ekwueme DU, Trogdon JG, Khavjou OA, Guy GP, Jr. (2016) Productivity Costs Associated With breast cancer among survivors aged 18-44 years. Am J Prev Med 50 (2):286-294. doi:10.1016/j.amepre.2015.10.006

7. Lindbohm ML, Kuosma E, Taskila T, Hietanen P, Carlsen K, Gudbergsson S, Gunnarsdottir H (2014) Early retirement and non-employment after breast cancer. Psychooncology 23 (6):634-641. doi:10.1002/pon.3459

8. Mehnert A, de Boer A, Feuerstein M (2013) Employment challenges for cancer survivors. Cancer 119 Suppl 11:2151-2159. doi:10.1002/cncr.28067

9. Quinlan E, Thomas-MacLean R, Hack T, Kwan W, Miedema B, Tatemichi S, Towers A, Tilley A (2009) The impact of breast cancer among Canadian women: disability and productivity. Work 34 (3):285-296. doi:10.3233/WOR-2009-0926

10. Ahn E, Cho J, Shin DW, Park BW, Ahn SH, Noh DY, Nam SJ, Lee ES, Yun YH (2009) Impact of breast cancer diagnosis and treatment on work-related life and factors affecting them. Breast Cancer Res Treat 116 (3):609-616. doi:10.1007/s10549-0080209-9

11. Calvio L, Peugeot M, Bruns GL, Todd BL, Feuerstein M (2010) Measures of cognitive function and work in occupationally active breast cancer survivors. J Occup Environ Med 52 (2):219-227. doi:10.1097/JOM.0b013e3181d0bef7

12. Carlsen K, Jensen AJ, Rugulies R, Christensen J, Bidstrup PE, Johansen C, Huitfeldt Madsen IE, Dalton SO (2013) Self-reported work ability in long-term breast cancer 
survivors. A population-based questionnaire study in Denmark. Acta Oncol 52 (2):423429. doi:10.3109/0284186X.2012.744877

13. Hansen JA, Feuerstein M, Calvio LC, Olsen CH (2008) Breast cancer survivors at work. J Occup Environ Med 50 (7):777-784. doi:10.1097/JOM.0b013e318165159e

14. Todd BL, Feuerstein EL, Feuerstein M (2011) When breast cancer survivors report cognitive problems at work. Int J Psychiatry Med 42 (3):279-294

15. Breckenridge LM, Bruns GL, Todd BL, Feuerstein M (2012) Cognitive limitations associated with tamoxifen and aromatase inhibitors in employed breast cancer survivors. Psychooncology 21 (1):43-53. doi:10.1002/pon.1860

16. Miaskowski C, Cooper B, Paul SM, West C, Langford D, Levine JD, Abrams G, Hamolsky D, Dunn L, Dodd M, Neuhaus J, Baggott C, Dhruva A, Schmidt B, Cataldo J, Merriman J, Aouizerat BE (2012) Identification of patient subgroups and risk factors for persistent breast pain following breast cancer surgery. J Pain 13 (12):1172-1187. doi:10.1016/j.jpain.2012.09.013

17. Karnofsky D (1977) Performance scale. Factors that influence the therapeutic response in cancer: a comprehensive treatise. Plenum Press, New York

18. Sangha O, Stucki G, Liang MH, Fossel AH, Katz JN (2003) The Self-Administered Comorbidity Questionnaire: a new method to assess comorbidity for clinical and health services research. Arthritis Rheum 49 (2):156-163. doi:10.1002/art.10993

19. Ferrell BR, Wisdom C, Wenzl C (1989) Quality of life as an outcome variable in the management of cancer pain. Cancer 63 (11 Suppl):2321-2327

20. Spielberger CG, Gorsuch RL, Suchene R, Vagg PR, Jacobs GA (1983) Manual for the State-Anxiety (Form Y): Self Evaluation Questionnaire. Consulting Psychologists Press, Palo Alto, CA

21. Radloff LS (1977) The CES-D Scale: A self-report depression scale for research in the general population. Applied Psychological Measurement 1 (3):385-401

22. Lee KA, Hicks G, Nino-Murcia G (1991) Validity and reliability of a scale to assess fatigue. Psychiatry Res 36 (3):291-298

23. Dhruva A, Dodd M, Paul SM, Cooper BA, Lee K, West C, Aouizerat BE, Swift PS, Wara W, Miaskowski C (2010) Trajectories of fatigue in patients with breast cancer before, during, and after radiation therapy. Cancer Nurs 33 (3):201-212.

doi:10.1097/NCC.0b013e3181c75f2a

24. Cimprich B, Visovatti M, Ronis DL (2011) The Attentional Function Index--a self-report cognitive measure. Psychooncology 20 (2):194-202. doi:10.1002/pon.1729

25. Fletcher BS, Paul SM, Dodd MJ, Schumacher K, West C, Cooper B, Lee K, Aouizerat B, Swift P, Wara W, Miaskowski CA (2008) Prevalence, severity, and impact of symptoms on female family caregivers of patients at the initiation of radiation therapy for prostate cancer. J Clin Oncol 26 (4):599-605. doi:10.1200/JCO.2007.12.2838 
26. Hox JJ, Moerbeek M, van de Shoot R (2017) Multilevel Analysis: Techniques and Applications. 3rd edn. Routledge Academic: Taylor \& Francis Group, New York: New York

27. Enders CK (2010) Applied Missing Data Analysis. Guilford Press, New York

28. Balak F, Roelen CA, Koopmans PC, Ten Berge EE, Groothoff JW (2008) Return to work after early-stage breast cancer: a cohort study into the effects of treatment and cancerrelated symptoms. J Occup Rehabil 18 (3):267-272. doi:10.1007/s10926-008-9146-z

29. Johnsson A, Fornander T, Rutqvist LE, Vaez M, Alexanderson K, Olsson M (2009) Predictors of return to work ten months after primary breast cancer surgery. Acta Oncol 48 (1):93-98. doi:10.1080/02841860802477899

30. Carlsen K, Dalton SO, Diderichsen F, Johansen C, Danish Cohort S (2008) Risk for unemployment of cancer survivors: A Danish cohort study. Eur J Cancer 44 (13):18661874. doi:10.1016/j.ejca.2008.05.020

31. Choi KS, Kim EJ, Lim JH, Kim SG, Lim MK, Park JG, Park EC (2007) Job loss and reemployment after a cancer diagnosis in Koreans - a prospective cohort study. Psychooncology 16 (3):205-213. doi:10.1002/pon.1054

32. Park JH, Park JH, Kim SG (2009) Effect of cancer diagnosis on patient employment status: a nationwide longitudinal study in Korea. Psychooncology 18 (7):691-699. doi:10.1002/pon.1452

33. Fantoni SQ, Peugniez C, Duhamel A, Skrzypczak J, Frimat P, Leroyer A (2010) Factors related to return to work by women with breast cancer in northern France. J Occup Rehabil 20 (1):49-58. doi:10.1007/s10926-009-9215-y

34. Petersson LM, Wennman-Larsen A, Nilsson M, Olsson M, Alexanderson K (2011) Work situation and sickness absence in the initial period after breast cancer surgery. Acta Oncol 50 (2):282-288. doi:10.3109/0284186X.2010.533191

35. Steiner JF, Nowels CT, Main DS (2010) Returning to work after cancer: quantitative studies and prototypical narratives. Psychooncology 19 (2):115-124. doi:10.1002/pon.1591

36. Veronesi U, Paganelli G, Viale G, Luini A, Zurrida S, Galimberti V, Intra M, Veronesi P, Robertson C, Maisonneuve P, Renne G, De Cicco C, De Lucia F, Gennari R (2003) A randomized comparison of sentinel-node biopsy with routine axillary dissection in breast cancer. N Engl J Med 349 (6):546-553. doi:10.1056/NEJMoa012782

37. Langford DJ, Paul SM, Cooper B, Kober KM, Mastick J, Melisko M, Levine JD, Wright F, Hammer MJ, Cartwright F, Lee KA, Aouizerat BE, Miaskowski C (2016) Comparison of subgroups of breast cancer patients on pain and co-occurring symptoms following chemotherapy. Support Care Cancer 24 (2):605-614. doi:10.1007/s00520-015-2819-1

38. Howell D, Oliver TK, Keller-Olaman S, Davidson JR, Garland S, Samuels C, Savard J, Harris C, Aubin M, Olson K, Sussman J, MacFarlane J, Taylor C (2014) Sleep 
disturbance in adults with cancer: a systematic review of evidence for best practices in assessment and management for clinical practice. Ann Oncol 25 (4):791-800.

doi:10.1093/annonc/mdt506

39. Saboonchi F, Petersson LM, Wennman-Larsen A, Alexanderson K, Vaez M (2015) Trajectories of anxiety among women with breast cancer: A proxy for adjustment from acute to transitional survivorship. J Psychosoc Oncol 33 (6):603-619.

doi:10.1080/07347332.2015.1082165

40. Kremser T, Evans A, Moore A, Luxford K, Begbie S, Bensoussan A, Marigliani R, Zorbas $\mathrm{H}$ (2008) Use of complementary therapies by Australian women with breast cancer.

Breast 17 (4):387-394. doi:10.1016/j.breast.2007.12.006

41. Wanchai A, Armer JM, Stewart BR (2010) Complementary and alternative medicine use among women with breast cancer: a systematic review. Clin J Oncol Nurs 14 (4):E45-55. doi:10.1188/10.CJON.E45-E55

42. de Boer AG, Taskila TK, Tamminga SJ, Feuerstein M, Frings-Dresen MH, Verbeek JH (2015) Interventions to enhance return-to-work for cancer patients. Cochrane Database Syst Rev (9):CD007569. doi:10.1002/14651858.CD007569.pub3

43. Stone DS, Ganz PA, Pavlish C, Robbins WA (2017) Young adult cancer survivors and work: a systematic review. J Cancer Surviv 11 (6):765-781. doi:10.1007/s11764-0170614-3 
Table 1 - Potential Predictors of the Intercept (I) and Linear Coefficient (LC) of the Impact of Cancer or Its Treatment on Employment

\begin{tabular}{|l|l|l|}
\hline Characteristic & I & LC \\
\hline Demographic characteristics & & \\
\hline Age & & \\
\hline Education & & \\
\hline Marital status & & \\
\hline Lives alone & & \\
\hline Ethnicity (white/nonwhite) & & \\
\hline Annual household income & & \\
\hline Employment status & & \\
\hline Hours worked per week & & \\
\hline Clinical Characteristics & & \\
\hline Body mass index & & \\
\hline Karnofsky Performance Status score & & \\
\hline Self-Administered Comorbidity Questionnaire score & & \\
\hline Gone through menopause & & \\
\hline Time since cancer diagnosis & & \\
\hline Stage of disease & & \\
\hline Type of surgery & & \\
\hline Sentinel lymph node biopsy & & \\
\hline Axillary lymph node dissection & & \\
\hline Received neoadjuvant chemotherapy & & \\
\hline Reconstruction at the time of surgery & & \\
\hline Symptoms & & \\
\hline Depression & & \\
\hline Trait anxiety & & \\
\hline State anxiety & & \\
\hline Fatigue & & \\
\hline Energy & & \\
\hline Attentional function & & \\
\hline Sleep disturbance & & \\
\hline Average pain & & \\
\hline Worst pain & & \\
\hline
\end{tabular}

= Significant in the exploratory analysis 
Table 2 - Demographic and Clinical Characteristics of the Patients $(n=387)$

\begin{tabular}{|c|c|}
\hline Characteristic & Mean (SD) \\
\hline Age (years) & $55.0(11.7)$ \\
\hline Education (years) & $15.7(2.6)$ \\
\hline Self-Administered Comorbidity Questionnaire score & $4.2(2.8)$ \\
\hline Karnofsky Performance Status score & $93.4(10.2)$ \\
\hline Body mass index $\left(\mathrm{kg} / \mathrm{m}^{2}\right)$ & $26.8(6.1)$ \\
\hline & $\%(\mathrm{n})$ \\
\hline Ethnicity - White & $65.6(254)$ \\
\hline Married/partnered (\% yes) & $40.8(158)$ \\
\hline Lives alone (\% yes) & $23.0(89)$ \\
\hline Currently employed (\% yes) & $48.1(186)$ \\
\hline Hours worked per week & $32.6(15.8)$ \\
\hline $\begin{array}{l}\text { Annual household income } \\
\quad<\$ 30,000 \\
\$ 30,000 \text { to }<\$ 70,000 \\
\$ 70,000 \text { to }<\$ 100,000 \\
\geq \$ 100,000\end{array}$ & $\begin{array}{l}20.3(65) \\
25.6(18) \\
16.3(52) \\
37.8(121) \\
\end{array}$ \\
\hline Gone through menopause prior to surgery (\% yes) & $64.9(251)$ \\
\hline Days since cancer diagnosis (mean (SD)) & $70.1(77.2)$ \\
\hline $\begin{array}{l}\text { Stage of disease } \\
\text { Stage } 0 \\
\text { Stage I } \\
\text { Stage Ila and Illb } \\
\text { Stage IIla, IIIb, IIIc, and IV }\end{array}$ & $\begin{array}{c}18.6(72) \\
38.5(149) \\
34.9(135) \\
8.0(31)\end{array}$ \\
\hline $\begin{array}{l}\text { Type of surgery } \\
\text { Breast conservation } \\
\text { Mastectomy }\end{array}$ & $\begin{array}{l}80.6(312) \\
19.4(75)\end{array}$ \\
\hline Sentinel lymph node biopsy (\% yes) & $83.2(322)$ \\
\hline Axillary lymph node dissection (\% yes) & $37.0(143)$ \\
\hline Underwent reconstruction at the time of surgery ( $\%$ yes) & $22.0(85)$ \\
\hline Received neoadjuvant therapy (\% yes) & $20.2(78)$ \\
\hline Pain in the affected breast prior to surgery (\% yes) & $27.1(105)$ \\
\hline Received radiation therapy during the 12 months following surgery (\% yes) & $71.1(275)$ \\
\hline Received chemotherapy during the 12 months following surgery (\% yes) & $34.4(133)$ \\
\hline Received hormonal therapy during the 12 months following surgery (\% yes) & $60.2(233)$ \\
\hline Received complimentary therapy in the 12 months following surgery (\% yes) & $32.8(127)$ \\
\hline Had breast reconstruction in the 12 months following surgery (\% yes) & $11.6(45)$ \\
\hline $\begin{array}{l}\text { Had re-excision or mastectomy on the affected breast in the six months } \\
\text { following surgery ( } \% \text { yes) }\end{array}$ & $30.2(117)$ \\
\hline Mean symptom severity scores at enrollment & Mean (SD) \\
\hline Trait anxiety score & $35.2(8.8)$ \\
\hline State anxiety score & $41.6(13.2)$ \\
\hline Center of Epidemiologic Studies-Depression Scale score & $13.6(9.6)$ \\
\hline Lee Fatigue Scale - fatigue score & $3.1(2.3)$ \\
\hline Lee Fatique Scale - energy score & $4.9(2.5)$ \\
\hline Attentional Function Index score & $6.6(1.9)$ \\
\hline General Sleep Disturbance Scale score & $48.1(21.3)$ \\
\hline
\end{tabular}




\begin{tabular}{|c|c|}
\hline Average pain intensity score in the breast prior to surgery & $0.6(1.3)$ \\
\hline Worst pain intensity score in the breast prior to surgery & $0.9(1.9)$ \\
\hline Degree that illness or treatment interfered with your employment & $3.2(3.7)$ \\
\hline
\end{tabular}


Table 3 - Unconditional and Joint Conditional Multilevel Linear Regression Models for Interference with Employment

\begin{tabular}{|c|c|c|}
\hline \multirow[t]{2}{*}{ Variable } & \multicolumn{2}{|c|}{ Coefficient (SE) } \\
\hline & $\begin{array}{c}\text { Unconditional } \\
\text { Model }\end{array}$ & Final Model \\
\hline \multicolumn{3}{|l|}{ Fixed effects } \\
\hline Intercept & $3.538(.183)+$ & $3.213(.177)+$ \\
\hline Time (linear rate of change) & $-0.076(.013)+$ & $-0.072(.015)+$ \\
\hline \multicolumn{3}{|l|}{ Intercept } \\
\hline Age & & $-0.098(.015)+$ \\
\hline Income & & $-0.194(.045)+$ \\
\hline Axillary lymph node dissection & & $1.283(.331)+$ \\
\hline Sentinel lymph node biopsy & & $0.529(.459)$ \\
\hline Worst pain score in the breast prior to surgery & & $0.163(.089)$ \\
\hline Sleep disturbance score & & $0.018(.008)^{*}$ \\
\hline \multicolumn{3}{|l|}{ Linear } \\
\hline Sentinel lymph node biopsy $x$ time & & $-0.109(.038)^{*}$ \\
\hline Sleep disturbance score $\mathrm{x}$ time & & $-0.002(.001)+$ \\
\hline \multicolumn{3}{|l|}{ Time varying covariates } \\
\hline Chemotherapy & & $0.460(.130)+$ \\
\hline Complementary or alternative therapy & & $0.434(.147)^{*}$ \\
\hline Re-excision or mastectomy of the affected breast & & $0.620(.195)^{*}$ \\
\hline
\end{tabular}

${ }^{*} p<.05,+p<.001$

Abbreviations: $\mathrm{SE}=$ standard error 
A.

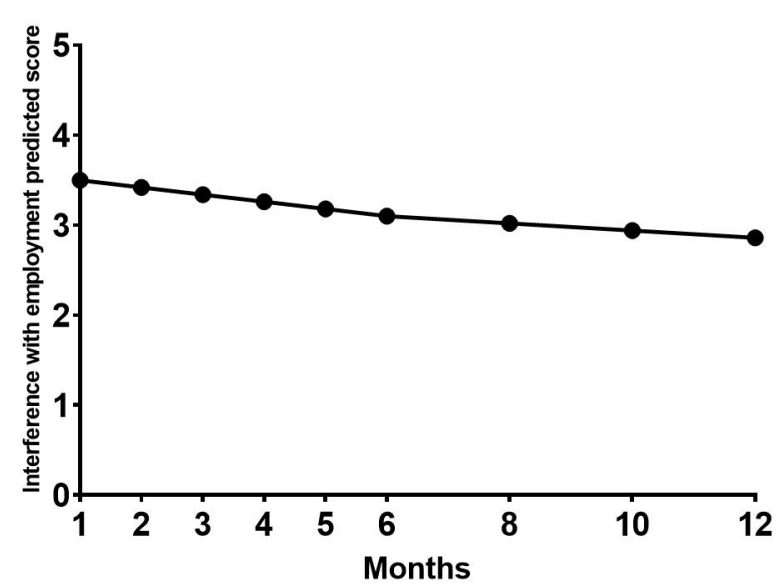

D.

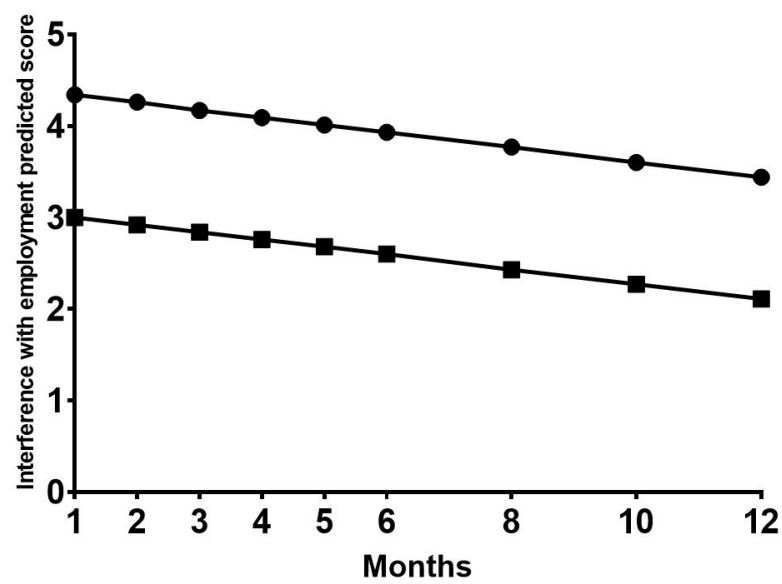

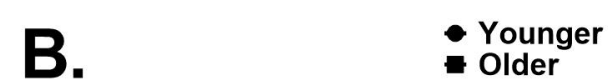

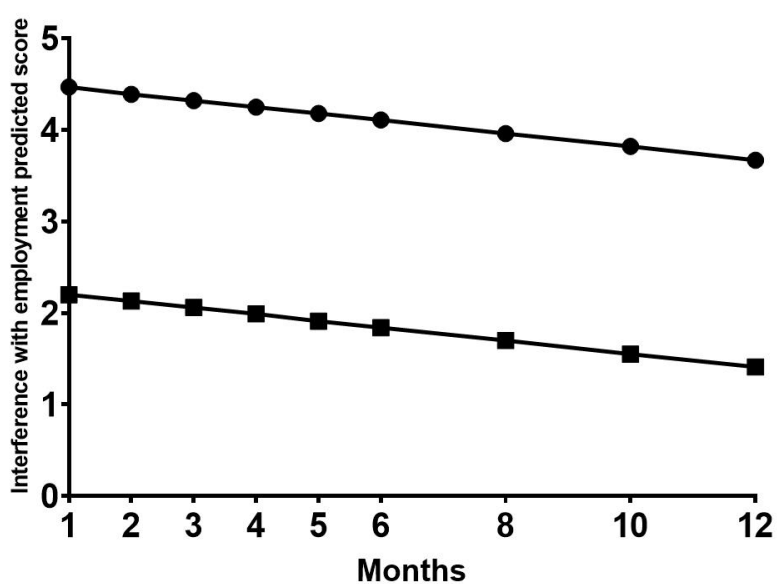

c.

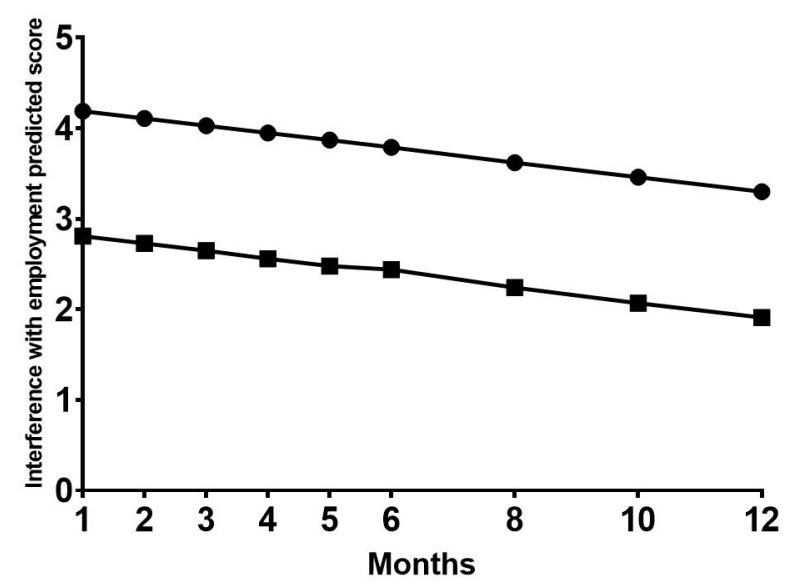

E.

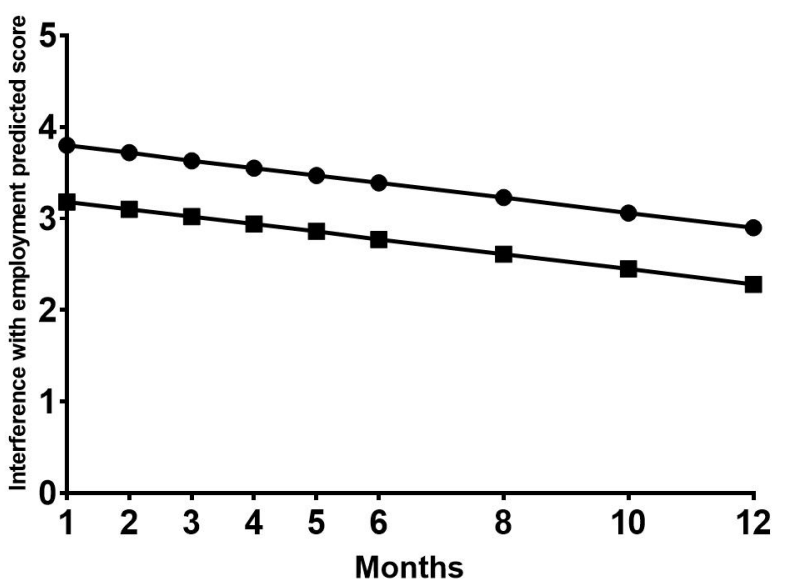


A.

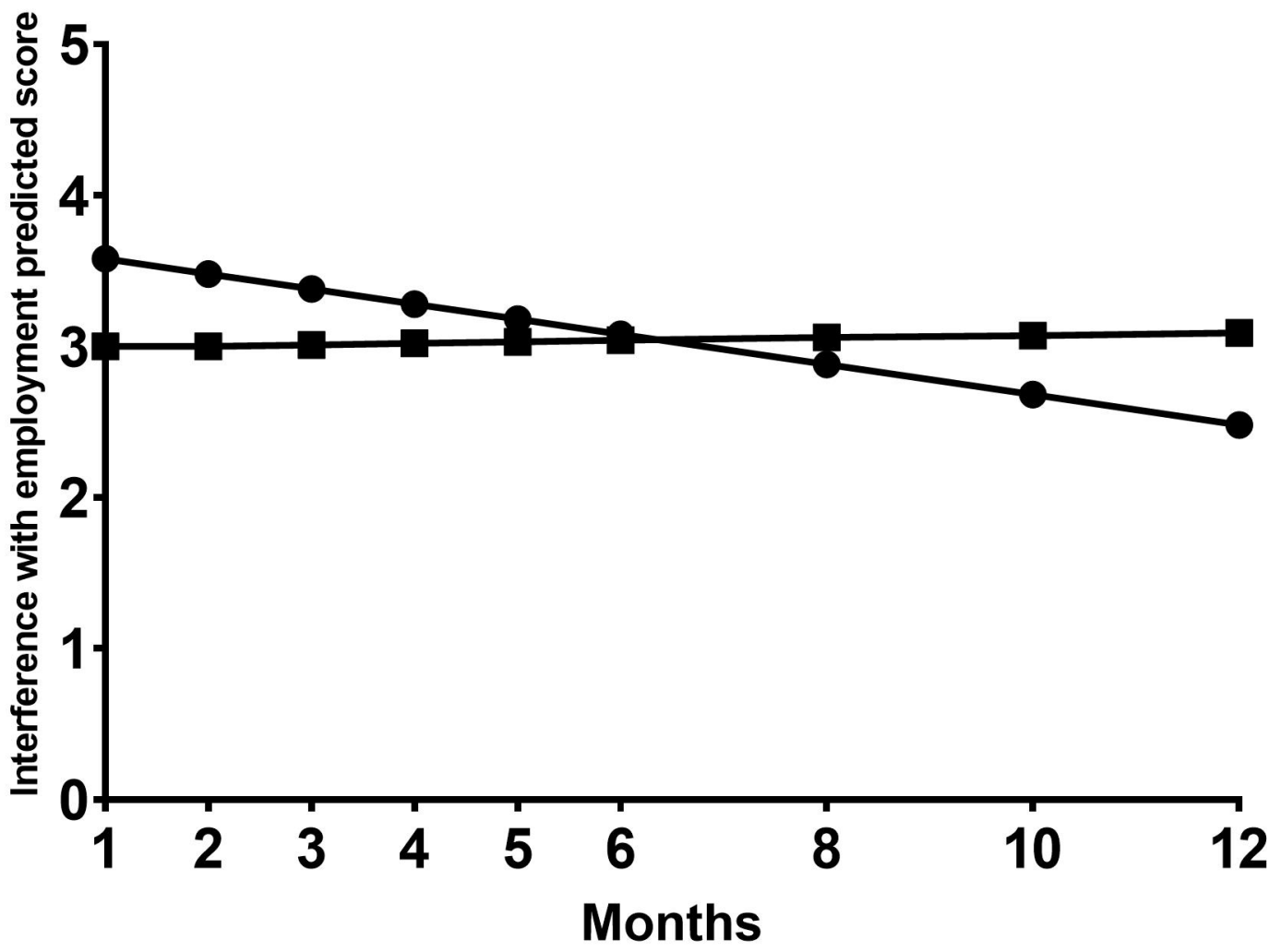

- Higher sleep disturbance

- Lower sleep disturbance

B.

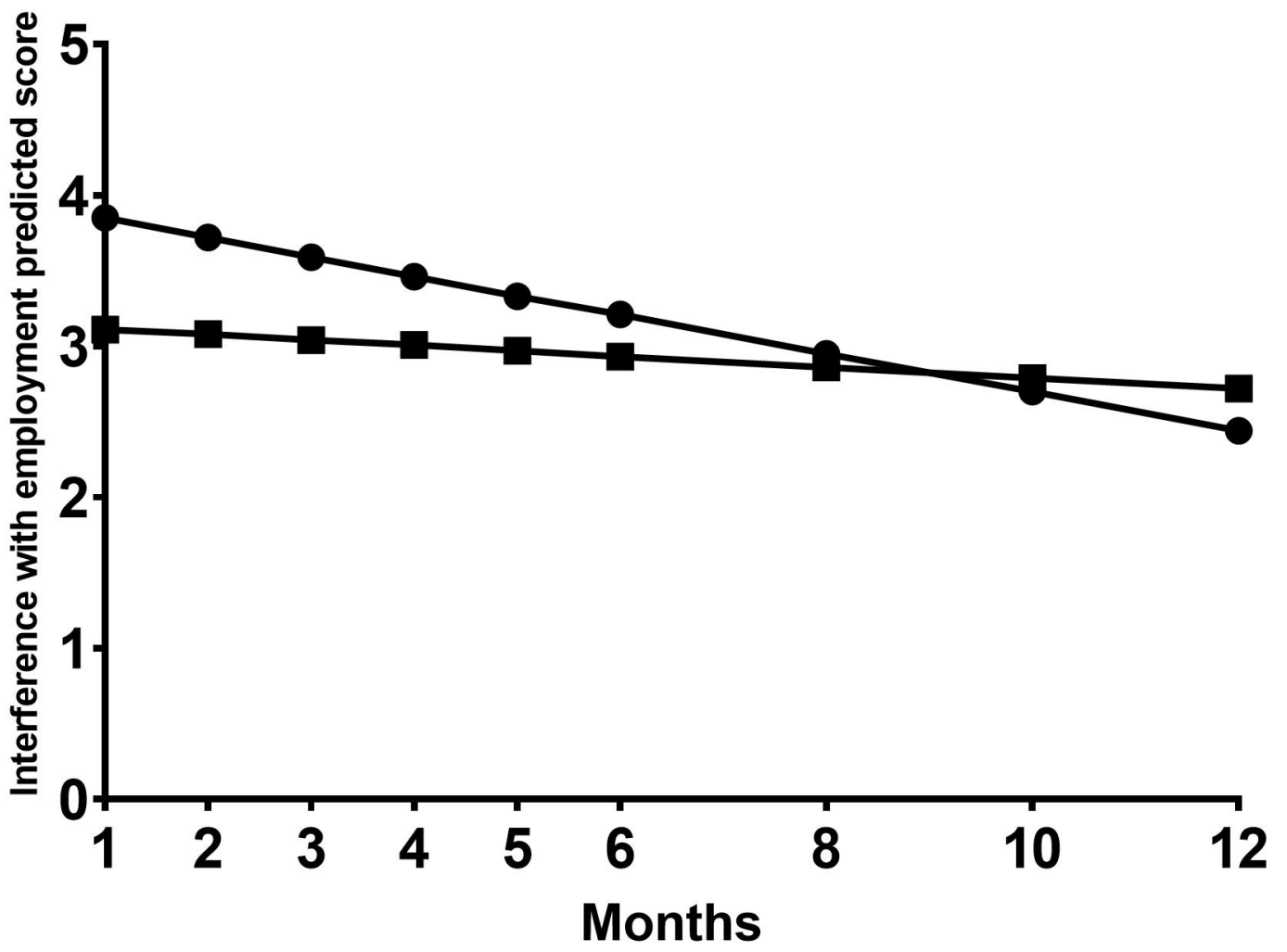

